\title{
CES
}

COOPERATIVISMO E ECONOMÍA SOCIAL

Núm. 43 (2020-2021), páxs. 191-203

ISSN: 2660-6348

\section{IMPUGNAÇÃO DA DELIBERAÇÃO DE EXCLUSÃO DE UM ASSOCIADO JUNTO DA ASSEMBLEIA GERAL \\ Comentário ao acórdão do Tribunal da Relação de Guimarães de 20 de fevereiro de 2020 (proc. n. ${ }^{\circ}$ 878/17.9T8PTL.G1)}

\section{APPEAL THE EXCLUSION RESOLUTION OF A MEMBER TO THE GENERAL MEETING}

Commentary on the Guimarães Court of Appeal decision of 20th February 2020 (proc. n. ${ }^{\circ}$ 878/17.9T8PTL.G1)

ANA AMORIM*

Doutora em Direito. Professora Auxiliar na Universidade Portucalense, Infante D. Henrique, Rua Dr. António Bernardino de Almeida, n. ${ }^{\circ}$ 541/619, 4200-072 Porto. Endereço de correio eletrónico: aamorim@upt.pt. 


\title{
RESUMEN
}

O texto aborda a anulabilidade da deliberação de exclusão de um associado tomada pelo órgão executivo da associação e a respetiva impugnação junto da assembleia geral, prevista no Regulamento Geral Interno. Tendo aquela impugnação sido qualificada como prévia e imperativa relativamente a uma eventual ação de anulação, fica inviabilizado o recurso direto a tribunal para arguição dos vícios da deliberação. O Tribunal da Relação de Guimarães considerou que restava apenas ao associado excluído a possibilidade de suscitar a convocação judicial da assembleia geral.

Palabras Clave: Associação, exclusão, assembleia geral, impugnação judicial direta, estatutos.

\begin{abstract}
The text addresses the annulability of the exclusion resolution of a member taken by the association's executive body and the respective appeal to the general meeting, as provided for in the General Internal Regulations. As that appeal has been qualified as prior and imperative in relation to a possible action for annulment, direct recourse to court to argue the resolution's defects is rendered impracticable. The Guimarães Court of Appeal considered that the excluded member only got the possibility of raising the judicial notification of the general meeting.
\end{abstract}

Keywords: Association, exclusion, general meeting, direct judicial appeal, statutes. 
SUMÁRIO: 1. FACTUALIDADE RELEVANTE E QUESTÕES SUSCITADAS; 2. ANULABILIDADE DA DELIBERAÇÃO DE EXCLUSÃO; 3. IMPUGNAÇÃO JUNTO DA ASSEMBLEIA GERAL; 3.1. Interpretação das normas regulamentares; 3.2. Convocação judicial; 4. CONCLUSÃO; 5. BIBLIOGRAFIA.

SUMMARY: 1. RELEVANT FACTUALITY AND ISSUES RAISED; 2. ANNULABILITY OF THE EXCLUSION RESOLUTION; 3. APPEAL TO THE GENERAL MEETING; 3.1. Interpretation of regulatory standards; 3.2. Judicial notification; 4. CONCLUSION. 5.BIBLIOGRAFY.

\section{FACTUALIDADE RELEVANTE E QUESTÕES SUSCITADAS}

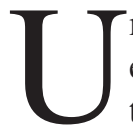

$\mathrm{m}$ membro de uma associação de artesãos intentou ação declarativa contra esta última, pedindo a declaração de nulidade da deliberação de exclusão tomada pela direção no dia 13 de julho de 2017, bem como a condenação no pagamento dos danos morais e patrimoniais sofridos. Para o efeito, o Autor invocou a falta de fundamentação daquela decisão, que assentava genericamente no incumprimento de "vários deveres estatutários e regulamentares" e em comportamentos não especificados, lesivos da associação e dos restantes associados. A Ré não contestou. Após a tramitação dos autos, a primeira instância julgou a ação totalmente improcedente, na medida em que o Autor promoveu diretamente em tribunal a declaração de nulidade da deliberação de exclusão, em desconformidade com o disposto no artigo 7..$^{\circ}$ do Regulamento Geral Interno da Ré, que previa a impugnação junto da assembleia geral.

Inconformado com a sentença proferida, o Autor interpôs recurso de apelação para o Tribunal da Relação de Guimarães. Para além do enquadramento dos vícios da deliberação no regime jurídico da anulabilidade, o acórdão de 20 de fevereiro de 2020 - aqui analisado - suscita a questão da qualificação da impugnação junto da assembleia geral prevista naquele Regulamento Geral Interno como prévia e imperativa relativamente a uma eventual ação de anulação. Ora, o Tribunal da Relação de Guimarães considerou que não poderia o associado excluído invocar judicialmente os vícios da deliberação, na ausência de recurso anterior para a assembleia geral. Neste sentido, julgou a apelação improcedente e confirmou a sentença recorrida.

\section{Anulabilidade da DEliberação de EXClusão}

O Autor invocou, relativamente à exclusão deliberada pela direção da Ré no dia 13 de julho de 2017, um conjunto de vícios de procedimento, nomeadamente, relativos à forma da deliberação, respetivas assinaturas e exercício do direito de 
voto dos membros. No entanto, invocou sobretudo os vícios de conteúdo inerentes à falta de fundamentação daquela decisão, na medida em que não concretizava quais as normas violadas pelo associado, comprometendo assim o exercício do contraditório.

Nos termos do artigo $177 .^{\circ}$ do CC, "as deliberações da assembleia geral contrárias à lei ou aos estatutos, seja pelo seu objeto, seja por virtude de irregularidades havidas na convocação dos associados ou no funcionamento da assembleia, são anuláveis". Considerando que o legislador não consagrou regimes jurídicos distintos para os vícios de procedimento e para os vícios de conteúdo, às deliberações sociais inválidas é aplicável o disposto no artigo $178 .^{\circ}$ do CC, nomeadamente quanto à legitimidade para a arguição da anulabilidade e ao respetivo prazo. Assim, a anulabilidade pode ser arguida "dentro do prazo de seis meses, pelo órgão da administração ou por qualquer associado que não tenha votado a deliberação".

Para acautelar a segurança jurídica, afastou-se o recurso ao artigo $294 .{ }^{\circ}$ do CC, que estabelece subsidiariamente a nulidade dos negócios jurídicos celebrados contra a lei. Trata-se de uma solução análoga à que resulta do artigo $58 .^{\circ} \mathrm{n} .{ }^{\circ} 1$ alínea a) do CSC relativo às sociedades comerciais e que assenta na teoria das deliberações em cadeia, na medida em que uma declaração de nulidade sem dependência de prazo seria suscetível de comprometer a subsistência dos negócios jurídicos entretanto celebrados pela pessoa coletiva. ${ }^{1}$ Esta opção legislativa tem sido igualmente reiterada pela jurisprudência, como resulta do acórdão do Supremo Tribunal de Justiça de 11 de dezembro de 2018 (proc. n. ${ }^{\circ}$ 6299/15.0T8LSB.L1.S1). ${ }^{2}$

Importa referir que aquela regra geral da anulabilidade das deliberações sociais foi consagrada a propósito do órgão deliberativo, aplicando-se por analogia também ao órgão executivo. Esta analogia - a que o Tribunal da Relação de Guimarães não alude - resulta do artigo $10 .^{\circ}$ do $\mathrm{CC}$, segundo o qual "os casos que a lei não preveja são regulados segundo a norma aplicável aos casos análogos" (n. ${ }^{\circ}$ 1) e "há analogia sempre que no caso omisso procedam as razões justificativas da regulamentação do caso previsto na lei" (n. $\left.{ }^{\circ} 2\right)$. Ou seja, nada justifica que a atuação do órgão executivo e, nomeadamente, a invalidade das suas deliberações, fique sujeita a um regime jurídico distinto daquele que foi consagrado para a assembleia geral.

1 P. OLAVO CUNHA, “Anotação ao artigo 177. (deliberações contrárias à lei ou aos estatutos)”, L. CARVALHO FERNANDES; J. BRANDÃO PROENÇA (coord.), Comentário ao Código Civil - Parte Geral, Universidade Católica Editora, Lisboa, 2014, p. 385.

2 A. AMORIM, "Anulação de deliberações sociais de associação por falta de convocatória para a assembleia geral. Comentário ao acórdão do Supremo Tribunal de Justiça de 11 de dezembro de 2018 (proc. n. ${ }^{\circ}$ 6299/15.0T8LSB.L1.S1)”, Cooperativismo e Economia Social, n. ${ }^{\circ} 41,2019$, p. 148. 
Na sequência do que vem sendo defendido pela doutrina, afirma-se no acórdão analisado que são excecionalmente nulas as deliberações cujo conteúdo seja contrário a norma imperativa, à ordem pública ou aos bons costumes, ou de objeto impossível, nos termos do artigo $280 .^{\circ}$ do CC. Apesar de não ter sido expressamente consagrada pelo legislador no caso das associações, a nulidade visa ainda a proteção de terceiros ou do interesse público. ${ }^{3}$ A estas deliberações aplica-se o disposto no artigo $286 .^{\circ}$ do CC, segundo o qual "a nulidade é invocável a todo o tempo por qualquer interessado e pode ser declarada oficiosamente pelo tribunal". No entanto, nem os vícios de procedimento, nem os vícios de conteúdo concretamente invocados pelo Autor, determinam a nulidade da deliberação de exclusão em causa. Pelo contrário, trata-se de uma invalidade que afeta apenas os interesses individuais dos membros atuais da associação, devendo considerar-se sanável por decurso do tempo.

\section{Impugnação junto da Assembleia Geral}

\subsection{Interpretação das normas regulamentares}

$\mathrm{O}$ artigo $167 .^{\circ}$ do CC consagra um conjunto de menções obrigatórias do ato de constituição da associação, entre as quais inclui "os bens ou serviços com que os associados concorrem para o património social, a denominação, fim e sede da pessoa coletiva, a forma do seu funcionamento, assim como a sua duração, quando a associação se não constitua por tempo indeterminado" (n. $\left.{ }^{\circ} 1\right)$, mas prevê também elementos de natureza facultativa dos respetivos estatutos, que abrangem "os direitos e obrigações dos associados, as condições da sua admissão, saída e exclusão, bem como os termos da extinção da pessoa coletiva e consequente devolução do seu património" (n. ${ }^{\circ}$ 2). Ao contrário do que se verifica relativamente aos primeiros, estes últimos elementos podem constar de normas regulamentares.

A propósito da perda da qualidade de membro, que está em causa no acórdão analisado, o legislador reiterou a proteção constitucional da liberdade de associação enunciada no artigo $46^{\circ}$ da CRP, que a par do direito subjetivo de associação (n. $\left.{ }^{\circ} 1\right)$, consagra a liberdade de organização interna da própria pessoa coletiva (n. ${ }^{\circ}$ 2). Sem prejuízo da fixação normativa de regras gerais, a liberdade de organização interna abrange a autonomia estatutária, bem como a liberdade de gestão e de escolha dos membros dos respetivos órgãos. ${ }^{4}$ Desta forma, na medida em que a matéria não cabe na competência reservada da assembleia geral, para

\footnotetext{
3 V. LOBO XAVIER, Anulação de Deliberação Social e Deliberações Conexas, Almedina, Coimbra, 1998, pp. 194-195.

4 GOMES CANOTILHO e VITAL MOREIRA, Constituição da República Portuguesa anotada, volume I, 4. ${ }^{a}$ edição, Coimbra Editora, Coimbra, 2007, pp. 644-646.
} 
os efeitos do artigo $172 .^{\circ}$ n. ${ }^{\circ} 2$ do $\mathrm{CC}$, remete-se para os estatutos a fixação do regime aplicável à exclusão dos associados, nomeadamente quanto aos respetivos fundamentos e competência.

Assim, os estatutos da Ré estabelecem que "os direitos e obrigações dos associados, suas categorias, condições de admissão e exclusão, constarão de um Regulamento Geral Interno, cuja aprovação e alteração são da exclusiva competência da Assembleia Geral" (artigo 4..$^{\circ}$ ). Consta então do referido Regulamento Geral Interno que compete à direção a exclusão dos associados com fundamento no incumprimento de deveres ou em comportamentos lesivos da associação e dos restantes associados (artigo $6 .^{\circ}$ n. ${ }^{\circ}$ 2) e que desta deliberação "cabe recurso para a Assembleia Geral a interpor pelo associado" (artigo 7. ${ }^{\circ}$ ). Importa referir que a atribuição de competência para a exclusão ao órgão executivo e o consequente direito de recurso do associado para a assembleia geral integra uma solução comum e maioritariamente apoiada pela doutrina. ${ }^{5}$

Ora, a questão central identificada no processo coincide com a interpretação das normas regulamentares referidas face a um eventual recurso direto a tribunal para arguição dos vícios da deliberação. Acompanhando a sentença proferida em primeira instância, o Tribunal da Relação de Guimarães afirmou que devia considerar-se afastada "a possibilidade de impugnação judicial direta de uma deliberação de expulsão tomada pelo respetivo órgão executivo", na medida em que o Regulamento Geral Interno da Ré consagrava "a sua prévia e imperativa impugnação junto do órgão assembleia geral". Neste sentido, ficaria o associado excluído impedido de "obter a declaração judicial de anulabilidade da dita deliberação, quando da mesma não tenha recorrido para o órgão assembleia geral". Apesar de o Autor ter alegado o recurso para a assembleia geral da deliberação de exclusão tomada pela direção da Ré no dia 13 de julho de 2017, este facto não foi provado e estava em contradição com outros demonstrados no processo.

Segundo o acórdão analisado, aquelas normas regulamentares inviabilizam a impugnação judicial direta das deliberações da direção em matéria de exclusão dos associados. A ação de anulação incidiria apenas sobre as deliberações da assembleia geral, não sobre as do órgão executivo. De acordo com o Tribunal da Relação de Guimarães, "compreende-se que assim seja, não só pela importância capital que se reveste tal matéria (devolvendo-se então a mesma ao órgão máximo da associação, enquanto conjunto de vontades que a constituem), como pela pretensão de assegurar um mínimo de intervenção externa na vida interna da associação (apenas a ela se recorrendo se o meio de impugnação interno não se mostrar suficiente)".

L. CARVALHO FERNANDES, Teoria Geral do Direito Civil, 6. ${ }^{a}$ edição, volume I, Universidade Católica Editora, Lisboa, 2012, p. 631. 
Resultaria do citado artigo 7. $^{\circ}$ do Regulamento Geral Interno da Ré a consagração de um mecanismo de arguição das invalidades das deliberações do órgão executivo junto da assembleia geral suscetível de precludir a respetiva impugnação judicial direta. Esta interpretação das normas regulamentares deve ser apreciada face ao disposto no artigo $20 .^{\circ}$ n. ${ }^{\circ} 1$ da CRP, que assegura a todos "o acesso ao direito e aos tribunais para defesa dos seus direitos e interesses legalmente protegidos, não podendo a justiça ser denegada por insuficiência de meios económicos". Também o artigo 2..$^{\circ}$ n. ${ }^{\circ} 2$ do $\mathrm{CPC}$, relativo à garantia de acesso aos tribunais, estabelece que "a todo o direito, exceto quando a lei determine o contrário, corresponde a ação adequada a fazê-lo reconhecer em juízo, a prevenir ou reparar a violação dele e a realizá-lo coercivamente, bem como os procedimentos necessários para acautelar o efeito útil da ação".

Do confronto com o regime jurídico aplicável a outras pessoas coletivas resulta que o problema da impugnação judicial direta das deliberações do órgão executivo se suscita igualmente a propósito do conselho de administração das sociedades anónimas. De acordo com o disposto no artigo 412 . $^{\circ}$ n. 1 do CSC, "o próprio conselho ou a assembleia geral pode declarar a nulidade ou anular deliberações do conselho viciadas, a requerimento de qualquer administrador, do conselho fiscal ou de qualquer acionista com direito de voto, dentro do prazo de um ano a partir do conhecimento da irregularidade, mas não depois de decorridos três anos a contar da data da deliberação". Esta arguição das invalidades perante órgãos sociais tem sido objeto de controvérsia na doutrina, sobretudo quanto à possibilidade de impugnação judicial direta. ${ }^{6}$ Ora, o problema aqui suscitado a propósito da interpretação da lei é semelhante ao que no acórdão analisado resulta do Regulamento Geral Interno da Ré, na parte em que estabelece que da deliberação de exclusão tomada pela direção "cabe recurso para a Assembleia Geral a interpor pelo associado”. Esta impugnação foi qualificada como prévia e imperativa relativamente a uma eventual ação de anulação.

Face ao artigo $412 .^{\circ}$ do CSC, alguns autores invocam a garantia de acesso aos tribunais para recusar a competência exclusiva do conselho de administração e da assembleia geral para apreciar as invalidades daquelas deliberações. ${ }^{7}$ No entanto, a questão não parece colocar-se hoje ao nível de uma eventual exclusividade, mas da possibilidade de impugnação judicial direta. O problema da inconstitucionalidade por violação do artigo $20 .^{\circ}$ da CRP viria a ser abordado pelo Tribunal Constitucional no paradigmático acórdão n. ${ }^{\circ}$ 415/2003, que considerou não resultar da norma em causa "a impossibilidade de o acionista sujeitar à sindicância jurisdicional a questão da validade da decisão do conselho de administração, isto através

6 J. M. COUTINHO DE ABREU, Governação das Sociedades Comerciais, 2. ${ }^{\text {a }}$ edição, Almedina, Coimbra, 2010, p. 136.

7 R. VENTURA, Estudos Vários sobre Sociedades Anónimas. Comentário ao Código das Sociedades Comerciais, Almedina, Coimbra, 1992, p. 559. 
da deliberação da assembleia geral que a não declare nula ou a não anule". Este mecanismo estaria justificado não só pela "relativa proeminência das assembleias gerais nos órgãos societários", como também por razões de ordem prática.

Uma parte da doutrina continua a recusar a possibilidade de impugnação judicial direta das deliberações do conselho de administração das sociedades anónimas, com fundamento na complexidade e insegurança geradas por uma eventual dualidade das formas de impugnação. ${ }^{8}$ Caberia em primeira linha aos sócios e não aos tribunais apreciar as invalidades daquelas deliberações. Pelo contrário, seguindo a posição maioritariamente adotada no direito comparado, a impugnação judicial direta tem sido acolhida por alguns autores nacionais, independentemente dos recursos previstos no artigo 412 . $^{\circ}$ do CSC ou em simultâneo com estes. ${ }^{9} \mathrm{Ou}$ seja, deve entender-se que não existe um recurso hierárquico necessário das deliberações do conselho de administração para a assembleia geral. ${ }^{10}$

Também a jurisprudência se tem dividido quanto à possibilidade de impugnação judicial direta das deliberações do conselho de administração das sociedades anónimas. Assim, o Tribunal da Relação de Coimbra no acórdão de 28 de junho de 2017, considerou que a eventual nulidade ou anulabilidade daquelas deliberações deve ser previamente submetida à apreciação da assembleia geral, "não só em função da relativa proeminência das assembleia gerais nos órgãos societários, como por razões de ordem prática, no sentido de evitar nocivas perturbações, ou paralisações, na atividade gestionária da sociedade" (proc. n. ${ }^{\circ}$ 1148/16.5T8GRD. C1). A impugnação judicial direta por um determinado acionista só seria admitida pontualmente, por exemplo, "relativamente a atos e omissões que lhe impeçam ou embaracem o exercício dos direitos inerentes às suas ações". Em sentido semelhante pronunciaram-se o Tribunal da Relação do Porto no acórdão de 4 de fevereiro de 2003 (proc. n. ${ }^{\circ}$ 0222397) e no acórdão de 15 de março de 2004 (proc. n. ${ }^{\circ}$ 0354886), bem como o Tribunal da Relação de Lisboa no acórdão de 13 de março de 2014 (proc. n. ${ }^{\circ}$ 1535/13.0TYLSB-A.L1-6) e no acórdão de 29 de setembro de 2016 (proc. $n .^{\circ}$ 1544/13.0TYLSB.L1-8).

Já no acórdão de 9 de janeiro de 2017, o Tribunal da Relação de Coimbra reconheceu a admissibilidade de impugnação judicial direta, dado que "impor o recurso em primeira linha à assembleia geral para reapreciação das deliberações do conselho de administração das sociedades anónimas poderá redundar numa perturbação da vida societária e será, em muitos casos, de uma perfeita inutili-

8 P. PAIS DE VASCONCELOS, A Participação Social nas Sociedades Comerciais, 2. ${ }^{a}$ edição, Almedina, Coimbra, 2006, p. 201.

9 J. M. COUTINHO DE ABREU, "Artigo 412. (arguição da invalidade de deliberações)", J. M. COUTINHO DE ABREU (coord.), Código das Sociedades Comerciais em Comentário, volume VI, 2. ${ }^{a}$ edição, Almedina, Coimbra, 2019, pp. 535-539.

10 J. PINTO FURTADO, Deliberações dos sócios. Comentário ao Código das Sociedades Comerciais, Almedina, Coimbra, 1993, p. 222. 
dade, como ocorrerá se os acionistas de controlo estiverem na administração da sociedade" (proc. n. ${ }^{\circ}$ 1365/14.2T8LRA.C1). Aquela admissibilidade tinha sido igualmente reconhecida pelo Tribunal da Relação do Porto no acórdão de 28 de setembro de 2010 (proc. n. ${ }^{\circ}$ 6328/07.1TBVFR.P1) e no acórdão de 27 de junho de 2011 (proc. n. ${ }^{\circ}$ 987/10.5TYVNG.P1).

No caso em apreço, poderia configurar-se como inútil a impugnação da deliberação de exclusão junto da assembleia geral, pelo que o mecanismo de arguição das invalidades das deliberações do órgão executivo não deve obstar ao recurso às vias comuns. Apesar de se reconhecer que razões de ordem prática aconselhem o recurso prévio à assembleia geral, o seu caráter imperativo não parece resultar necessariamente das referidas normas regulamentares. No entanto, o Tribunal da Relação de Guimarães, inspirado na doutrina e na jurisprudência que recusam a impugnação judicial direta das deliberações do conselho de administração das sociedades anónimas, não apreciou os vícios da deliberação de exclusão em causa no processo. Acresce que, à semelhança do que se verifica para os efeitos do artigo 412. ${ }^{\circ}$ do CSC, deve ser privilegiada a interpretação das normas regulamentares que melhor garanta o direito de acesso aos tribunais consagrado no artigo $20 .^{\circ} \mathrm{n} .^{\circ}$ 1 da CRP.

\subsection{Convocação judicial}

O Autor afirmou a dificuldade de convocar a assembleia geral, decorrente do alegado mau funcionamento dos órgãos sociais da Ré. Seguindo ainda a posição adotada pela primeira instância, o Tribunal da Relação de Guimarães reconheceu que, face à impossibilidade de impugnar judicialmente a deliberação de exclusão tomada pela direção, o associado excluído poderia recorrer ao processo especial de convocação da assembleia geral previsto no artigo $1057 .^{\circ}$ n. ${ }^{\circ} 1$ do CPC a propósito das sociedades. Assim, "se a convocação de assembleia geral puder efetuar-se judicialmente, ou quando, por qualquer forma, ilicitamente se impeça a sua realização ou o seu funcionamento, o interessado requer ao juiz a convocação".

A convocação judicial da assembleia geral traduz um mecanismo destinado a suprir a inércia dos órgãos sociais competentes. No quadro das sociedades comerciais, de acordo com o artigo $248 .^{\circ}$ n. 3 do CSC, aplicável às sociedades por quotas, e do artigo $377 .^{\circ}$ n. ${ }^{\circ} 1$ do $\mathrm{CSC}$, aplicável às sociedades anónimas, têm competência para convocar o órgão deliberativo, respetivamente, qualquer gerente e o presidente da mesa da assembleia geral. A possibilidade de convocação judicial abrange quer a assembleia geral anual quer outra reunida extraordinariamente, ainda que se trate de assembleias especiais de titulares de categorias diferenciadas de ações. Abrange igualmente as assembleias de obrigacionistas, nos termos do 
artigo $355 .^{\circ}$ n. ${ }^{\circ} 3$ do CSC. ${ }^{11}$ A consagração deste processo especial justifica-se num contexto em que os sócios não têm competência para convocar a assembleia geral, sob pena de nulidade das deliberações tomadas, nos termos do artigo $56 .^{\circ}$ n. ${ }^{\circ} 2$ do CSC.

Também o artigo $63 .^{\circ}$ n. ${ }^{\circ} 1$ alínea b) do Estatuto das Instituições Particulares de Solidariedade Social, aprovado pelo DL n. ${ }^{\circ}$ 119/83, de 25 de fevereiro, a propósito das associações de solidariedade social, prevê que qualquer associado e o Ministério Público podem requerer ao tribunal competente a convocação do órgão deliberativo "quando, por alguma forma, esteja a ser impedida a convocação da assembleia nos termos legais ou se impeça o seu funcionamento, com grave risco ou ofensa dos interesses da instituição, dos associados ou do Estado". Deve aplicar-se neste caso o processo especial previsto no artigo $1057 .^{\circ}$ do CPC quanto à convocação de assembleia geral das sociedades.

No entanto, relativamente às associações, o artigo $173 .^{\circ}$ n..$^{\circ} 3$ do $\mathrm{CC}$ prevê que "se a administração não convocar a assembleia nos casos em que deve fazêlo, a qualquer associado é lícito efetuar a convocação". Este direito conferido a qualquer associado apenas pode ser exercido quando a administração não faça a convocação a que estava obrigada, "nas circunstâncias fixadas pelos estatutos e, em qualquer caso, uma vez em cada ano para aprovação do balanço" (n. $\left.{ }^{\circ} 1\right)$ ou "sempre que a convocação seja requerida, com um fim legítimo, por um conjunto de associados não inferior à quinta parte da sua totalidade, se outro número não for estabelecido nos estatutos" (n. $\left.{ }^{\circ} 2\right)$. A norma estabelece um dever legal de convocar que impende sobre a administração, cujo incumprimento determina a possibilidade de qualquer associado realizar a convocação, sem necessidade de recurso a tribunal. ${ }^{12}$ Neste sentido, trata-se de um direito subsidiário relativamente à atuação da administração. ${ }^{13}$

Importa referir que, para os efeitos desta convocação, pode estar em causa também o incumprimento de um dever estatutário, que na prática impende frequentemente sobre o presidente da mesa da assembleia geral. ${ }^{14}$ Em qualquer outro caso, as deliberações tomadas em assembleia geral convocada por um associado padecem de um vício de procedimento, sendo anuláveis de acordo com o disposto no artigo $177 .^{\circ}$ do CC. Esta solução afasta-se da que resulta para as sociedades

11 J. LABAREDA, "Notícia sobre os processos destinados ao exercício de direitos sociais", Direito e Justiça, volume 13, tomo 1, 1999, pp. 87-88.

12 A. AMORIM, "Competência para convocar a assembleia geral de uma associação. Comentário ao acórdão do Tribunal da Relação do Porto de 22 de maio de 2019 (proc. n. ${ }^{\circ}$ 3578/18.9T8VFR.P1)", Cooperativismo e Economia Social, n. ${ }^{\circ} 42,2020$, p. 165.

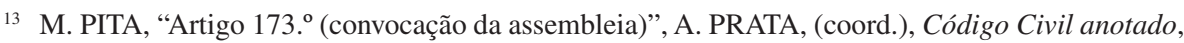
volume I, 2. a edição, Almedina, Coimbra, 2019, pp. 226-227.

${ }^{14}$ A. MENEZES CORDEIRO, Tratado de Direito Civil, volume IV - Parte Geral. Pessoas, 5. a edição, Almedina, Coimbra, 2019, p. 821. 
comerciais do artigo $56 .^{\circ}$ n..$^{\circ} 2$ do $\mathrm{CSC}$, que equipara à falta de convocatória as hipóteses em que o aviso seja assinado por quem não tenha competência.

Ao contrário do que se verifica nas sociedades comerciais, o legislador consagrou a propósito das associações esta possibilidade de os respetivos membros convocarem a assembleia geral perante a inércia do órgão executivo. Assim se justifica que, no acórdão de 19 de fevereiro de 1991, o Tribunal da Relação do Porto tenha afirmado que o processo especial previsto no artigo $1057 .^{\circ}$ do CPC traduz um "meio privativo das sociedades comerciais ou das sociedades civis sob forma comercial, não aplicável às associações stricto sensu, em que aos associados é permitida a convocação, nos termos do artigo $173 .^{\circ}$ n. 3 do CC" (proc. n. ${ }^{\circ}$ 0500597). Já no quadro das fundações, tem sido defendida pela doutrina a aplicação analógica das normas relativas à convocação judicial, nomeadamente aquelas que o legislador consagrou a propósito das associações de solidariedade social no Estatuto das Instituições Particulares de Solidariedade Social, aprovado pelo DL n. ${ }^{\circ}$ 119/83, de 25 de fevereiro. Tal aplicação analógica funda-se sobretudo na ausência de um mecanismo semelhante ao que resulta para as associações do citado artigo $173 .^{\circ}$ n. ${ }^{\circ} 3$ do CC..$^{15}$

Em suma, o processo especial previsto no artigo $1057 .^{\circ}$ do CPC para as sociedades, aplicável analogicamente às fundações, e a possibilidade de convocar a assembleia geral das associações reconhecida aos respetivos membros no artigo $173 .^{\circ}$ n. ${ }^{\circ} 3$ do $\mathrm{CC}$ constituem mecanismos destinados a suprir a inércia dos órgãos sociais competentes, nos casos em que se verifique o incumprimento de um dever legal ou estatutário de realizar a convocação. No entanto, no caso em apreço, não parecem estar verificados os pressupostos da obrigatoriedade de convocação, nem sequer ao abrigo das normas regulamentares. Desta forma, restaria eventualmente ao associado excluído o recurso ao requerimento conjunto a que alude o artigo $173 .^{\circ}$ n. ${ }^{\circ} 2$ do $\mathrm{CC}$ e não ao processo especial previsto no artigo $1057 .^{\circ}$ do CPC. Ou seja, o associado não podia ter suscitado a convocação judicial da assembleia geral.

\section{Conclusão}

O Tribunal da Relação de Guimarães não apreciou os vícios da deliberação de exclusão do Autor tomada pela direção da Ré no dia 13 de julho de 2017, que decorriam sobretudo da respetiva falta de fundamentação. Na medida em que estava em causa uma deliberação meramente anulável, nos termos do artigo $177 .^{\circ}$ do CC, esta invalidade deve considerar-se sanável por decurso do tempo.

15 H. SOUSA ANTUNES, "Fundações: a aplicação analógica de normas sobre a convocação judicial de assembleia geral", Cadernos de Direito Privado, n. ${ }^{\circ}$ 19, julho/setembro 2007, p 64. 
A questão central identificada no processo decorre da qualificação da impugnação junto da assembleia geral prevista nas normas regulamentares da associação como prévia e imperativa relativamente a uma eventual ação de anulação. Ora, ao contrário do que se afirma no acórdão analisado, não parece resultar do artigo 7. $^{\circ}$ do Regulamento Geral Interno da Ré a consagração de um mecanismo de arguição das invalidades das deliberações do órgão executivo junto da assembleia geral suscetível de precludir a respetiva impugnação judicial direta. Assim se tem entendido hoje maioritariamente na doutrina e na jurisprudência a propósito das deliberações do conselho de administração das sociedades anónimas, para os efeitos do artigo $412 .^{\circ}$ do CSC. Neste sentido, não parece ter sido privilegiada a interpretação das normas regulamentares que melhor garante o direito de acesso aos tribunais consagrado no artigo $20 .^{\circ} \mathrm{n} .{ }^{\circ} 1$ da CRP.

Face à alegada impossibilidade de impugnar judicialmente a deliberação de exclusão tomada pela direção, o associado não poderia igualmente recorrer ao processo especial de convocação da assembleia geral previsto no artigo $1057 .^{\circ} \mathrm{n} .{ }^{\circ}$ 1 do CPC a propósito das sociedades, dado que não se verifica o incumprimento de um dever legal ou estatutário de realizar a convocação pelos órgãos sociais competentes.

\section{Bibliografia}

ABREU, Jorge Manuel Coutinho de, Governação das Sociedades Comerciais, 2.. edição, Almedina, Coimbra, 2010.

— "Artigo 412. (arguição da invalidade de deliberações)", ABREU, Jorge Manuel Coutinho de (coord.), Código das Sociedades Comerciais em Comentário, volume VI, 2. ${ }^{\text {a }}$ edição Almedina, Coimbra, 2019, pp. 530-540.

AMORIM, Ana, "Anulação de deliberações sociais de associação por falta de convocatória para a assembleia geral. Comentário ao acórdão do Supremo Tribunal de Justiça de 11 de dezembro de 2018 (proc. n. ${ }^{\circ}$ 6299/15.0T8LSB.L1.S1)", Cooperativismo e Economia Social, n. ${ }^{\circ}$ 41, 2019, pp. 145-156.

- "Competência para convocar a assembleia geral de uma associação. Comentário

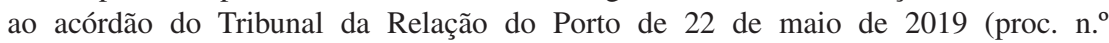
3578/18.9T8VFR.P1)", Cooperativismo e Economia Social, n. ${ }^{\circ}$ 42, 2020, pp. 161-173.

ANTUNES, Henrique Sousa, "Fundações: a aplicação analógica de normas sobre a convocação judicial de assembleia geral", Cadernos de Direito Privado, n. ${ }^{\circ} 19$, julho/setembro 2007, pp. 58-71.

CANOTILHO, Gomes; MOREIRA, Vital, Constituição da República Portuguesa anotada, volume I, 4. ${ }^{\text {a }}$ edição, Coimbra Editora, Coimbra, 2007.

CORDEIRO, António Menezes, Tratado de Direito Civil, volume IV - Parte Geral. Pessoas, 5. ${ }^{a}$ edição, Almedina, Coimbra, 2019.

CUNHA, Paulo Olavo, “Anotação ao artigo 177. (deliberações contrárias à lei ou aos estatutos)”, FERNANDES, Luís Carvalho; PROENÇA, José Brandão (coord.), Comentário ao Código Civil - Parte Geral, Universidade Católica Editora, Lisboa, 2014, pp. 384-386. 
FERNANDES, Luís Carvalho, Teoria Geral do Direito Civil, 6. ${ }^{a}$ edição, volume I, Universidade Católica Editora, Lisboa, 2012.

FURTADO, Jorge Pinto, Deliberações dos sócios. Comentário ao Código das Sociedades Comerciais, Almedina, Coimbra, 1993.

LABAREDA, João, "Notícia sobre os processos destinados ao exercício de direitos sociais", Direito e Justiça, volume 13, tomo 1, 1999, pp. 43-111.

PITA, Manuel, "Artigo 173. (convocação da assembleia)", PRATA, Ana (coord.), Código Civil

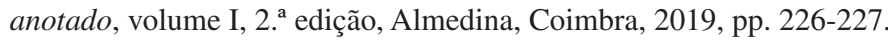

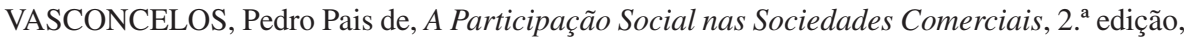
Almedina, Coimbra, 2006.

VENTURA, Raúl, Estudos Vários sobre Sociedades Anónimas. Comentário ao Código das Sociedades Comerciais, Almedina, Coimbra, 1992.

XAVIER, Vasco da Gama Lobo, Anulação de Deliberação Social e Deliberações Conexas, Almedina, Coimbra, 1998. 